\title{
WEAR ANALYSIS OF VARIES TEMPERED SAMPLE OF STAINLESS STEEL 420B
}

\section{Indrajeet $S$. Gurav}

Department of Mechanical Design Engineering Rajarambapu Institute of Technology, Islampur, Sangli, India

\begin{abstract}
Stainless steel widely used because it has good mechanical property and moderate corrosion resistance. Till the date lot of research work on medical, automobile and submarine has been done, but in nuclear plant limited work on Wear and lot of more research work need to be study. (E.g. Nuclear reactor, Piston cylinder, Mixer blade). The wear analysis of a stainless steel (SS-420B) against alumina balls was investigated in nitric acid solution. The present study aims to compare the coefficient of friction of varies austenized tempered sample of SS-420B at rated temperature. Wear analysis was investigated of $300^{\circ} \mathrm{c}$, $550^{\circ} \mathrm{c}, 7^{\circ}{ }^{\circ} \mathrm{c}, 1020^{\circ} \mathrm{c}$ and degradation was observed in scanning electron microscope in $50 \mathrm{ml}$ Nitric acid solution
\end{abstract}

Keywords - Linear Reciprocating Tribometer, Wear, Scanning electron microscope, Nitric acid

\section{INTRODUCTION}

Stainless Steel can be defined as iron based alloys that contain a minimum of about $12 \mathrm{wt} . \% \mathrm{Cr}$, the amount needed to guarantee a high corrosion resistance by the formation of a passivating oxide film [10]. This amount of $\mathrm{Cr}$ needs to be dissolved within the metallic matrix in order to ensure passivation. While the $\mathrm{Fe}-\mathrm{Cr}$ system forms the basis, modern stainless steels, besides $\mathrm{Cr}$, also contain other alloying elements. Martensite stainless steel that provides increase strength and hardness [1,3]. That why will we understand mechanical properties was changed ion heat treatment [1] .In heat treatment process annealing, hardening tempering are included. Stainless steel mostly commonly used in steam generator, dental, surgical, pump shaft, plastics molds and dies, piston cylinder [1-5].

The aim of research is to analyzed the effect of autenized and tempering sample of mechanical properties based on wear morphology

\author{
Dr. Sanjaykumar.S.Gavade \\ Department of Mechanical Design Engineering \\ Rajarambapu Institute of Technology, Islampur, \\ Sangli, India
}

\section{EXPERIMENTATION}

\section{A. Chemical Analysis and Material prepartation -}

The energy dispersive X-ray fluorescence spectroscopy (XRF) is a method for measuring thickness of coatings and for analyzing materials composition. It can be used for the qualitative and quantitative determination of the elemental composition of a material sample as well as for measuring coatings and coating systems.

The Stainless steel SS-420B was analyzed by using XRF. The table 5.2 shows the results of XRF analysis. The experimental steel are performed in vacuum furnace. The chemical composition of stainless steel $420 \mathrm{~B}$ as shown in table

\begin{tabular}{|c|c|c|}
\hline $\begin{array}{c}\text { Sr. } \\
\text { No }\end{array}$ & Element & Composition(\% or ppm) \\
\hline 1 & $\mathrm{Si}$ & $126 \mathrm{ppm}$ \\
\hline 2 & $\mathrm{P}$ & $212 \mathrm{ppm}$ \\
\hline 3 & $\mathrm{~V}$ & $165 \mathrm{ppm}$ \\
\hline 4 & $\mathrm{Cr}$ & $10.9 \%$ \\
\hline 5 & $\mathrm{Fe}$ & $80.5 \%$ \\
\hline 6 & $\mathrm{Ni}$ & $0.2 \%$ \\
\hline 7 & $\mathrm{Cu}$ & $0.1 \%$ \\
\hline 8 & $\mathrm{Mo}$ & $0.1 \%$ \\
\hline 9 & $\mathrm{C}$ & $4511 \mathrm{ppm}$ \\
\hline 10 & $\mathrm{~S}$ & $45 \mathrm{ppm}$ \\
\hline
\end{tabular}

A cutting sample is sealed in a quartz tube with helium gas for the austenitization heat treatment. Austenitization was done at $1020^{\circ} \mathrm{C}$ for 30 minutes. Tempering and annealing both processes take place on the same processing equipment and involve heating the glass to approximately $1020^{\circ} \mathrm{C}$ for $30 \mathrm{~min}$ and then air cooling will done, if force-cooling done it will create surface and edge compression. Which process is required depends on the specific application of the glass. Subsequently, the austenitized specimens were tempered at 300,550 and $700^{\circ} \mathrm{C}$ for a period of $2.5 \mathrm{~h}$ followed by air 


\section{International Journal of Engineering Applied Sciences and Technology, 2020 \\ Vol. 5, Issue 5, ISSN No. 2455-2143, Pages 67-71 \\ Published Online September 2020 in IJEAST (http://www.ijeast.com)}

cooling. The austenitization and tempering heat treatments were chosen based on reported studies on AISI 420B SS [1].

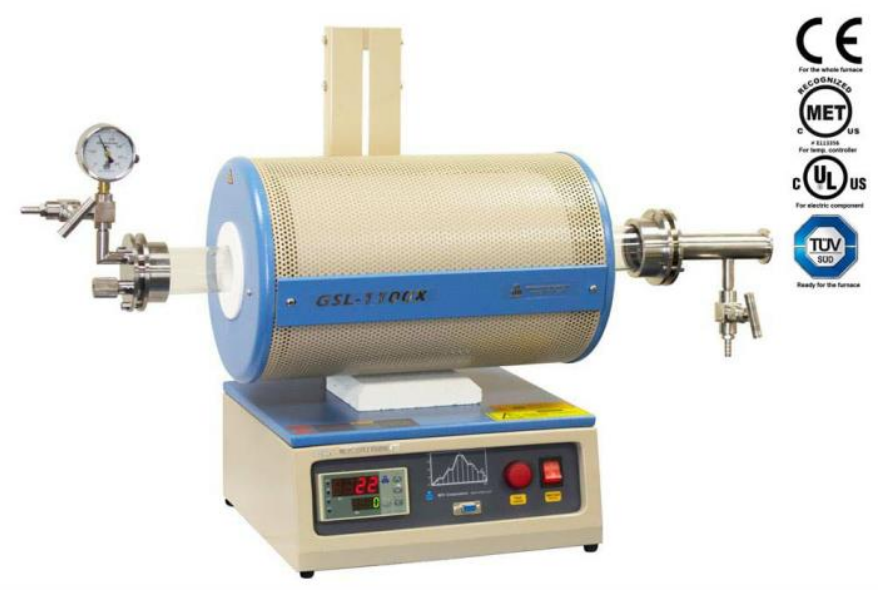

Fig. 1. Mini Vaccum Furnace

\section{B. Experimental Procedure -}

The current setup is linear reciprocating tribometer setup with lubricant testing facility is available at BARC, Mumbai. The linear reciprocating tribometer is typically floor standing model, having interfaced with a PC for sequence control and data acquisition facility with software for determining frictional force and coefficient of friction to estimate the wear characteristics of a sample material. The principle is to press a top specimen against a bottom specimen under dry, lubricant (oil and water) and heated condition. The upper specimen moves in linear reciprocating motion under different conditions set with load, frequency and temperature while stroke length fixed at $0.5,1.0,1.5$ and $2 \mathrm{~mm}$. The load is applied by upper specimen pressing horizontal mounted flat bottom specimen. The frequency, stroke length, temperature and test duration are input into the software, load is applied via dead weight and value is entered into the software for the calculation of coefficient of friction. After test dimensional changes/mass losses for both top and bottom specimen are used to calculate wear volume and wear rate during test.

The experiments were carried out in stainless steel (SS$420 \mathrm{~B}$ ) of varies tempered sample of $1020^{\circ} \mathrm{c}, 550^{\circ} \mathrm{c}, 700^{\circ} \mathrm{c}$ and $300^{\circ} \mathrm{c}$ of $100 \mathrm{~N}$ load at operating speeds of $25 \mathrm{~Hz}$ respectively. The stroke length of reciprocating tribometer is kept at $1 \mathrm{~mm}$. The plan is based on study of behavior of stainless steel of varies tempered sample along with constant sliding velocity and constant stroke length. The each experiment was carried out for duration of 90 minutes. All experiments are carried out at room temperature of $25^{\circ} \mathrm{C}$. The experiment was carried in nitric acid solution.
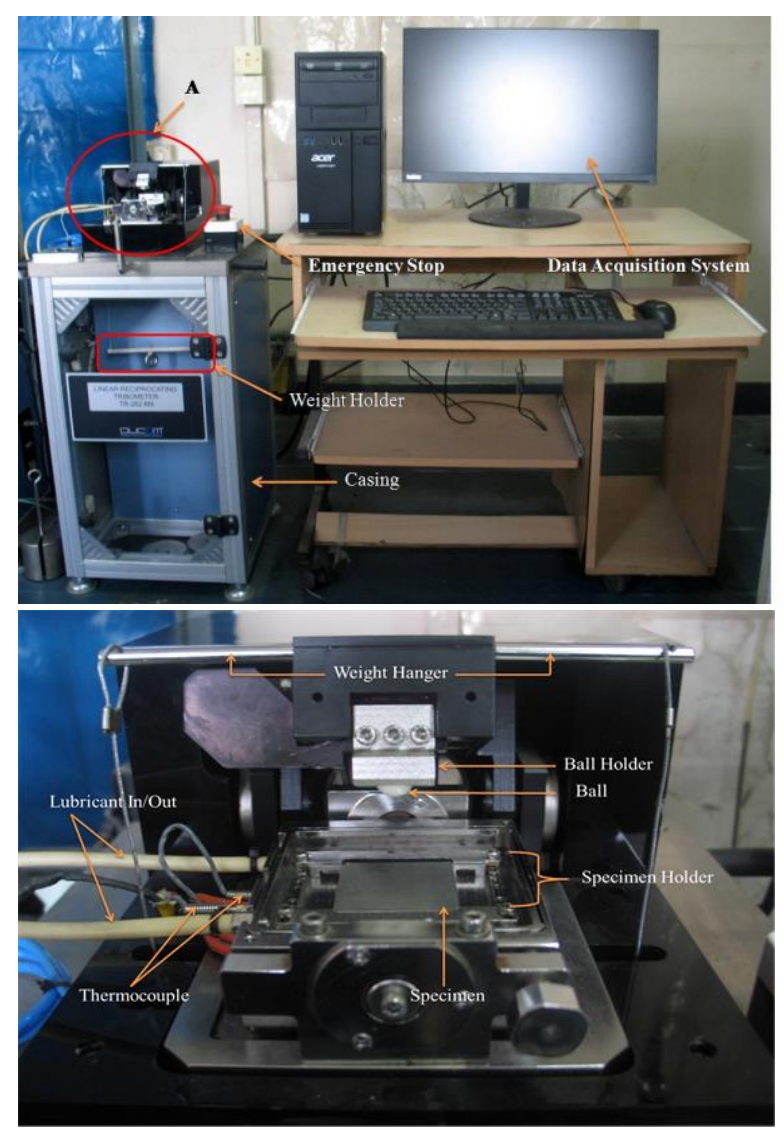

Fig. 2. Linear Reciprocvating Tribometer setup

After Conducting test Mass loss measurement using precision balance measured, especially when the worn surface is irregular and unsymmetrical in shape. Sample to be measured is carefully cleaned, and the weight is measured before and after a wear test. The difference between weight before and after test represents the weight loss caused by wear.

A wear test where corrosion is a possible factor is performed after the specimen is cleaned. Volume loss rates per unit exposed area are then calculated. The value of $T$ is obtained from these measurements. By using density and exposed area, weight loss is converted into volume loss/exposed aea $(\mathrm{mm} 3 / \mathrm{mm} 2)$. The results are shown below.

$$
\mathrm{T}=\frac{\mathrm{Wt} \text { loss }}{[\mathrm{A}]_{\mathrm{e}}+\mathrm{P}}=\frac{\mathrm{mm}^{3}}{\mathrm{~mm}^{2}}
$$

Where,

$$
\begin{gathered}
{[\mathrm{A}]_{\mathrm{e}}=\text { Exposed area }\left(\mathrm{mm}^{2}\right)} \\
\mathrm{P}=\text { Specific density }\left(\mathrm{g} / \mathrm{mm}^{3}\right)
\end{gathered}
$$




\section{International Journal of Engineering Applied Sciences and Technology, 2020 \\ Vol. 5, Issue 5, ISSN No. 2455-2143, Pages 67-71 \\ Published Online September 2020 in IJEAST (http://www.ijeast.com)}

\section{EXPERIMENTAL RESULT}

\section{A. Wear loss result:-}

The Experimental sample was tested in Linear reciprocating tribometer are result are shown in data acqusion system. For acquiring result Windicom software was used. After conducting test the Wt. loss was measured, using Wt. loss, exposed area and specific density material loss was obtained. The material loss value of all experimental sample are shown below.

Table No- 1 Experimental Result

\begin{tabular}{|c|c|c|c|c|c|}
\hline $\begin{array}{c}\text { Test } \\
\text { samp } \\
\text { le }\end{array}$ & $\begin{array}{c}\text { Wt. } \\
\text { ball(Be } \\
\text { fore) }\end{array}$ & $\begin{array}{c}\text { Wt. } \\
\text { ball(aft } \\
\text { er) }\end{array}$ & $\begin{array}{c}\text { Wt. } \\
\text { before } \\
\text { sample }\end{array}$ & $\begin{array}{c}\text { Wt. } \\
\text { after } \\
\text { sample }\end{array}$ & $\begin{array}{c}\text { Material loss } \\
\mathrm{T}\end{array}$ \\
\hline $\begin{array}{c}1020 \\
{ }^{\circ} \mathrm{c}\end{array}$ & 1.7851 & 1.7851 & 4.1837 & 4.1750 & $8.6932^{*} 10-4$ \\
\hline $\begin{array}{c}550^{\circ} \\
\mathrm{c}\end{array}$ & 1.7851 & 1.7851 & 4.5020 & 4.4989 & $3.0975^{*} 10-4$ \\
\hline $\begin{array}{c}700^{\circ} \\
\mathrm{c}\end{array}$ & 1.7851 & 1.7851 & 5.1238 & 5.1209 & $2.8977 * 10-4$ \\
\hline $\begin{array}{c}300^{\circ} \\
\mathrm{c}\end{array}$ & 1.7851 & 1.7851 & 5.4384 & 5.4370 & $1.3989 * 10-4$ \\
\hline
\end{tabular}

From above table we will observed that material loss of $300{ }^{\circ} \mathrm{c}$ sample having minimum loss as compared to other sample. As well as $700{ }^{\circ} \mathrm{c}$ sample having material loss was also minimum compare to $550^{\circ} \mathrm{C}$ and $1020^{\circ} \mathrm{c}$, then $550^{\circ} \mathrm{c}$ and $1020^{\circ} \mathrm{c}$.

The autenized stainless steel sample having less mechanical resistance as compare to other and high rate of wear occurs after the dissolution of passive film. The wear loos and corrosive particle gets involved in rubbing surfaces and $1020^{\circ} \mathrm{c}$. In stainless steel $300^{\circ} \mathrm{C}$ sample having good mechanical resistance and less wear was observed after conducting test.

\section{B. COF Vs. Time Graph:-}

The average coefficient of friction is calculated by averaging the set of stabilized data points from plot of coefficient of friction against time. The Coefficient of friction calculated in wet condition (At nitric acid) at varies temperature specimen of stainless steel SS-420B, and compare coefficient of friction is depend or not on material grain structure

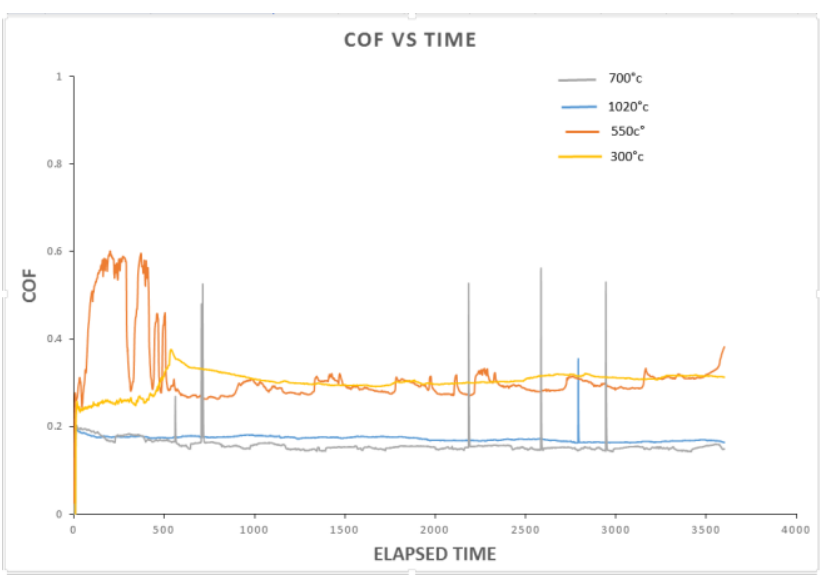

Fig. 3. Coefficient of Friction vs. Time graph

The behavior of coefficient of friction vs. time at $100 \mathrm{~N}$ load is shown in fig.3. From fig. it has shown that the coefficient of friction $300^{\circ} \mathrm{c}$ sample higher than other stainless steel sample. This graph shows that higher frictional force in $300^{\circ} \mathrm{c}$ for $100 \mathrm{~N}$ when load will increasing the coefficient of friction will decrease. The less coefficient of friction shows it cannot sustained the higher load at desired time because it is inversely proportional to load.

The behavior of coefficient of friction vs time against time at $100 \mathrm{~N}$ load are very similar to results obtained under load of above fig

\section{Worm Surface and Wear Debris Morphology:-}

The test samples are analyzed by an optical microscope as well as Scanning electron microscope (SEM) with study of interest in wear track and the vicinity of wear track. From SEM we will observe pit, blow holes, starches and corrosion attack on specimen.

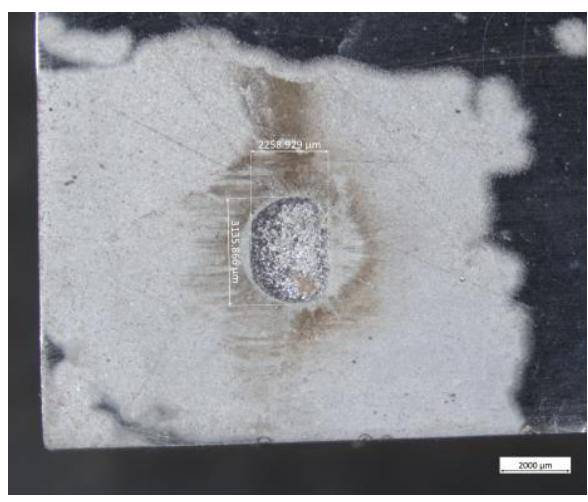

Fig (a) Material loss of $300^{\circ} \mathrm{c}$ sample 
International Journal of Engineering Applied Sciences and Technology, 2020

Vol. 5, Issue 5, ISSN No. 2455-2143, Pages 67-71

Published Online September 2020 in IJEAST (http://www.ijeast.com)

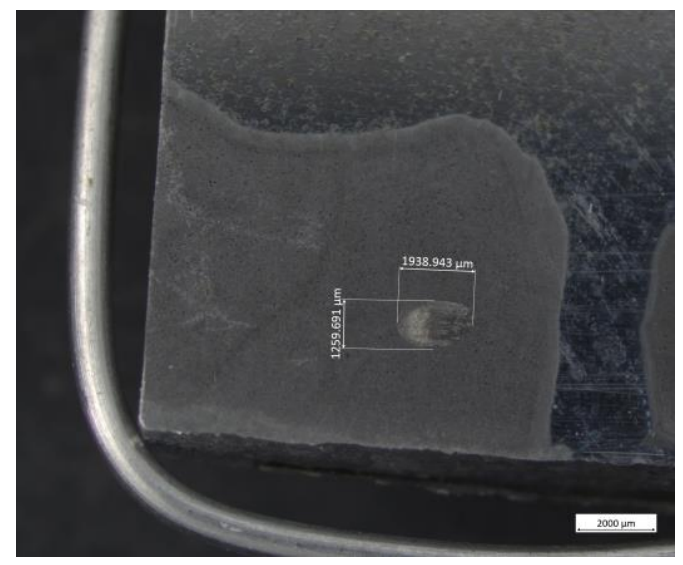

Fig (b) Material loss of $550^{\circ} \mathrm{c}$ sample

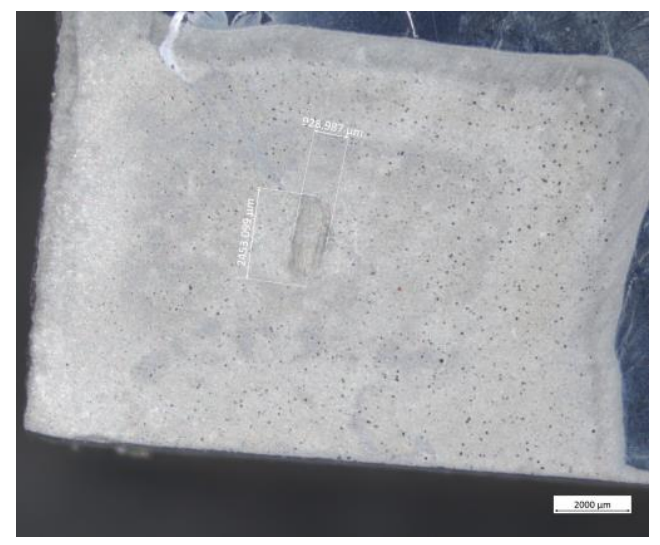

Fig (c) Material loss of $700^{\circ} \mathrm{c}$ sample

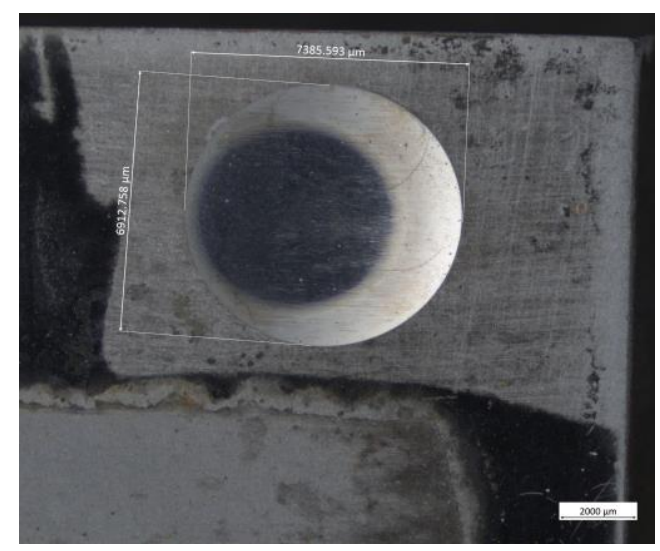

Fig (a) Material loss of $1020^{\circ} \mathrm{c}$ sample

From Optical Microscope observed that $1020^{\circ} \mathrm{c}$ sample having high rate of wear occurs after the dissolution of passive film. The wear loos and corrosive particle gets involved in rubbing surfaces of $1020^{\circ} \mathrm{C}$. In $300{ }^{\circ} \mathrm{C}$ and $550{ }^{\circ} \mathrm{C}$ having less wear are occur and less rate corrosive dissolution are occurs. In $1020^{\circ} \mathrm{c}$ sample the depth of wear are also high are wear track width are also high. In $700{ }^{\circ} \mathrm{c}$ and $300^{\circ} \mathrm{c}$ sample exposed area was clearly seen, but in $550{ }^{\circ} \mathrm{c}$ and $1020^{\circ} \mathrm{c}$ sample exposed area was not clearly seen. In $300^{\circ} \mathrm{C}$ sample corrosion attack was clearly indicated in brown color other than sample.

\section{CONCLUSION}

The effect heat treatment parameters on Wear was studied following conclusion:

1. A good Material loss properties are achieved of Stainless Steel (SS 420B) $300^{\circ} \mathrm{C}$ and $700^{\circ} \mathrm{c}$ sample.

2. The behavior of COF vs. Time Graph of $300{ }^{\circ} \mathrm{C}$ sample are higher than other.

3. From optical microscope we will observe higher width of wear track and much more wear occur of $1020{ }^{\circ} \mathrm{C}$ sample, and $700{ }^{\circ} \mathrm{C}$ sample having less wear and wear track width was achieved.

\section{REFERENCE}

[1] A. Nasery Isfahany, H.Saghafian, G.Borhani (2011) using The effect of Heat treatment on mechanical properties and corrosion bheviour of AISI 420 martensitic stainless steel: Journal of alloy and component (pg 3931-3936)

[2] D.Holmes, S.Sharifi, M.M.stack (2014) using Tribocorrosion of steel artificial saliva on Tribology International (Pg80-86)

[3] Yun-tao Xi, Dao- Xin Liu, Dong Han, (2007) using Improvement of corrosion and Wear Resistance of AISI 420 martensitic Stainless steel using plasma Nitriding at low temperature on surface and coatings technology (Pg2577-2583).

[4] Xiulin Ji, Biao Hu, Yixian Li, Shuqi Wang (2015) using Sliding Tribocorrosion behavior of bulk metallic glass against bearing steel in 3.5\% $\mathrm{NaCl}$ solution on Tribology International (Pg214-220).

[5] J.Perret, E.Boehm-Courjault, M.Cantoni et.al (2010) using EBSD, SEM and FIB Characterization of subsurface deformation during tribocorrosion of stainless steel in sulphuric acid on Wear Journal (Pg383-393).

[6] Arkaniusz Stachowiak, Wies aw Zwierzycki (2011) using Tribocorrosion modeling of stainless steel in a sliding pair of pin on plate type on Tribology International (Pg12161224) 
[7] J. Jiang, M.M. Stack and A. Neville (2002) using Modelling the Tribocorrosion Interaction in Aqueous Sliding Conditions on Tribology International (Pg669679).

[8] Yan Wang, Lei Zhang, Jet.al (2016) using The tribocorrosion behaviour of $\mathrm{Cu}-9 \mathrm{wt} \% \mathrm{Ni}-6 \mathrm{wt} \% \mathrm{Sn}$ alloy on Tribology International (Pg260-268).

[9] Danilo Fontes Ferreira, Sergio Matheus Ale Almeida et.al(2011) using Synergism between Mechanical Wear and Corrosion on Tribocorrosion of a Titanium Alloy in a Ringer Solution on journal of material and technology (pg1593-1600)

[10] K.LDahm (2006) using Direct Observation Of The Interface During Sliding Tribocorrosion on Tribology International (pg1561-1267).

[11] M.M.Stack (2002) using Mapping Tribocorrosion Processes in Dry and in Aqueous Conditions: some new directions for the new millennium on Tribology International (Pg681-689).

[12] A.Lopez-ortega, J.L.Arana and R.bayon(2018) using Tribocorrosion of Passive Materials: A Review on Test Procedure and Standards on International Journal Of corrosion(Pg 206-214)

[13] B.Bozteps, A.C.Alves and F. Toptan (2018) using A Comparative investigation of the corrosion and tribocorrosion behaviour of nitro carburized, gas nitrided, fluidizied-bed nitrided, and plasma nitride plastic mould steel on Surface and coatings technology(Pg16-123).

[14] D.Landolt,S.Mischler, M.Stemp (2001) using Electrochemical methods in tribocorrosion: a critical appraisal on Electrochimica Acta (Pg3913-3929).

[15] R. Mehul(2003) using Discrete Wavelet Transform Based Multiple Watermarking Scheme on in Proceedings of the IEEE TENCON(Pg935-938). 